2 Hu ZJ, Iwama H, Suzuki R, Kobayashi S, Akutsu I. Time course of activated coagulation time at various sites during continuous haemodiafiltration using nafamostat mesilate. Intensive Care Med 1999; 25: 524-7.

3 Kox WJ, Robr U, Wauer H. Practical aspects of renal replacement therapy. Int J Artif Organs 1996; 19: $100-5$.

\section{Aspiration pneumonia associated with a giant epiglottic cyst after cardiac surgery}

To the Editor:

Epiglottic cysts are found incidentally during induction of general anesthesia and can hamper tracheal intubation. ${ }^{1}$ Several methods have been reported to overcome these situations, however, to our knowledge, there has been no report of postoperative respiratory complications in patients with epiglottic cysts. We describe a patient with a giant asymptomatic epiglottic cyst who developed aspiration pneumonia after cardiac surgery.

A 7l-yr-old man (height $154 \mathrm{~cm}$, weight $42 \mathrm{~kg}$ ) was scheduled to undergo coronary artery bypass grafting. During induction of general anesthesia, a giant epiglottic cyst was found (Figure). Though manual ventilation was easy, the cyst had almost obstruct-

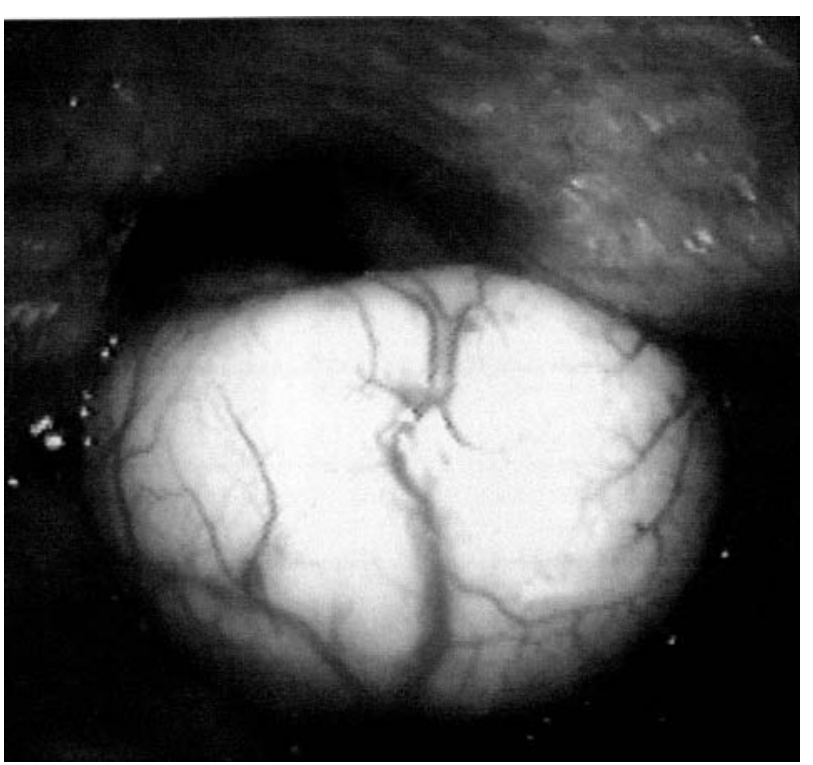

FIGURE A giant epiglottic cyst was found incidentally at laryngoscopy. The larynx was almost obstructed by the cyst. ed the larynx and tracheal intubation was difficult. The surgery was carried out uneventfully and he was admitted to the intensive care unit for postoperative management. On postoperative day one (PODl), he was extubated and his respiratory state was stable. On POD2, he was able to drink water and the cough reflex was present. Immediately following the reintroduction of solid food, he developed aspiration pneumonia of the right lower lobe. Mechanical ventilation and administration of antibiotics proved effective and the cyst was removed surgically on POD5 under general anesthesia. The postoperative course after cystectomy was uneventful and oral intake was normal.

There are several factors that increase the risk for aspiration pneumonia after surgery; namely, loss of protective airway reflexes, vomiting, pregnancy, obesity, diminished level of consciousness, anatomic distortion of the airway and a history of cerebrovascular disease. ${ }^{2,3}$ Especially after cardiac surgery, age and duration of intubation are independent predictors of swallowing dysfunction. ${ }^{4}$ In our patient, age, the residual effects of anesthetics, the use of transesophageal echocardiography, duration of intubation and anatomic distortion due to the giant epiglottic cyst are all possible factors explaining aspiration. We cannot tell which factor was predominant. However, the presence of this large epiglottic cyst may have resulted in postoperative epiglottic dysfunction and aspiration of solid food.

\section{MinHye So MD \\ Kazuya Sobue MD PhD \\ Hajime Arima MD \\ Tetsuro Morishima MD \\ Masatoshi Fukumoto MD \\ Sayuki Tanaka MD \\ Hiroshi Ando MD PhD \\ Obazaki, Japan \\ Hirotada Katsuya MD PhD \\ Nagoya, Japan}

\section{References}

1 Dada MA. Laryngeal cyst and sudden death. Med Sci Law 1995; 35: 72-4.

2 Mecca RS. Pulmonary aspiration syndrome. In: Kirby RR, Gravenstein N, Lobato EB, Gravenstein JS (Eds.). Clinical Anesthesia Practice, 2nd ed. Philadelphia: W.B. Saunders Company; 2002: 101-3.

3 Harrington $O B$, Duckworth JK, Starnes CL, et al. Silent aspiration after coronary artery bypass grafting. Ann Thorac Surg 1998; 65: 1599-603.

4 Hogue CW Jr, Lappas GD, Creswell LL, et al. Swallowing dysfunction after cardiac operations. 
Associated adverse outcomes and risk factors including intraoperative transesophageal echocardiography. J

Thorac Cardiovasc Surg 1995; 110: 517-22.

\section{Ventilation of a patient after esophageal intubation with a double- lumen tube}

To the Editor:

Sometimes, intubation with a double-lumen tube (DLT) is difficult. We present a patient who was ventilated after esophageal intubation with a DLT used like an esophageal-endotracheal combitube (EEC). A 66-yr-old female patient $(155 \mathrm{~cm}, 74 \mathrm{~kg}$, body mass index $=31$ ) was scheduled for thymectomy for gradeI myasthenia gravis. Her thyromental distance was less than $6 \mathrm{~cm}$ and difficult intubation was predicted. General anesthesia was induced with $70 \mathrm{mg}$ propofol and $0.1 \mathrm{mg}$ fentanyl, and maintained with $4 \%$ sevoflurane. She was intubated without using a muscle relaxant with a 35 Fr-Left-DLT (Sheridan, Tyco, Tokyo, Japan). Her Cormack's laryngoscopic view was grade 3. Although the DLT could not be advanced more

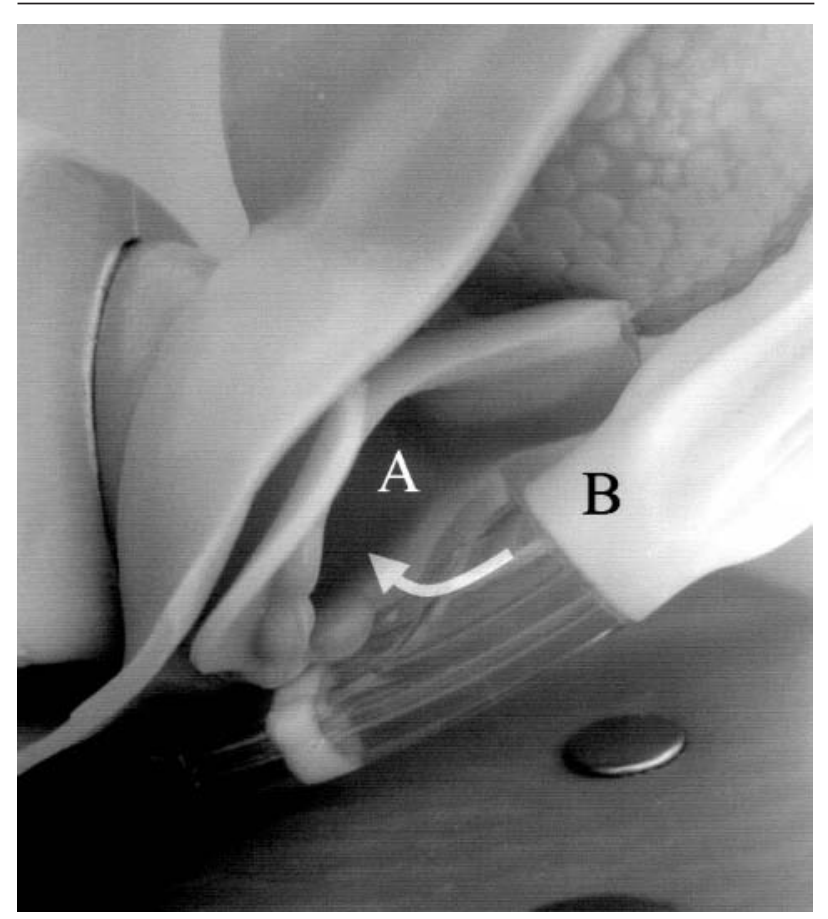

FIGURE Relationship between the vocal cords and the tracheal lumen of a double- lumen tube (DLT). The bronchial lumen is inserted in the esophagus. A, vocal cords; B, tracheal lumen of the DLT. than $21 \mathrm{~cm}$ from the patient's incisors, endotracheal intubation was assumed when spontaneous breathing re-appeared rapidly and capnography detected a normal $\mathrm{CO}_{2}$ waveform. However, the patient could not be ventilated mechanically. Subsequent fibroscopy via the bronchial lumen revealed esophageal intubation. The bronchial lumen compressed the posterior wall of the esophageal inlet, while the tracheal lumen opened just posterior to the arytenoid cartilages (Figure). In this case, the DLT performed as an EEC. Grmec reported that capnography was the most reliable method to confirm esophageal intubation, ${ }^{1}$ since the $\mathrm{CO}_{2}$ waveform generally decreases to zero, even if an initial pulse of swallowed $\mathrm{CO}_{2}$ is sensed. However, repeated airway evaluations should be performed to prevent a misdiagnosis such as occurred in our case, rather than depending on capnography alone.

Junichi Ogata MD

Toru Yokoyama MD

Kouichiro Minami MD PhD

Fukuoka, Japan

\section{Reference}

1 Grmec $S$. Comparison of three different methods to confirm tracheal tube placement in emergency intubation. Intensive Care Med 2002; 28: 701-4.

\section{Management choices for the difficult airway}

\section{To the Editor:}

We read with great concern the article by Jenkins et al. (October 2002). ${ }^{1}$ Their survey showed that in "Clinical Scenario number 3 - Laryngeal tumour with stridor for laryngectomy," 90\% of anesthesiologists would perform an awake intubation, $45 \%$ of which would use fibreoptic bronchoscope (FOB) and 38\% a lighted stylet.

This is very dangerous practice and could result in death of the patient. Best anesthetic practice is either 1) gas induction of anesthesia, maintaining spontaneous respiration, and when deep enough using a rigid laryngoscope (our preference is the tubular Lindholm scope as it opens up the posterior pharyngeal space and pushes tumour or edema out of the way). 2) If the patient is deemed to have an extremely compromised airway then an awake surgical tracheostomy is indicated. ${ }^{2}$

Awake FOB intubation is totally contraindicated in this scenario for the following reasons: 